Research Article

\title{
Outbreaks in India: Impact on Socio-economy and Health
}

\author{
Divya Sanghi', Preeti Saini' ${ }^{2}$ Priya Mishra ${ }^{3}$, Mahak Sharma $^{4}$ \\ ${ }^{1,4}$ Associate Professor, ${ }^{3}$ Assitant Professor, Department of Nutrition and Dietetics, Faculty of Allied Health Sciences, Manav \\ Rachna International Institute of Research and Studies, Faridabad, Haryana, India. \\ ${ }^{2}$ Assitant Professor, Department of Physiotherapy, Faculty of Allied Health Sciences, Manav Rachna International Institute of \\ Research and Studies, Faridabad, Haryana, India.
}

DOI: https://doi.org/10.24321/0019.5138.202107

\section{I $\quad \mathbf{N} \quad \mathbf{F} \quad \mathbf{O}$}

\author{
Corresponding Author: \\ Mahak Sharma, Department of Nutrition and \\ Dietetics, Faculty of Allied Health Sciences, \\ Manav Rachna International Institute of Research \\ and Studies, Faridabad, Haryana, India. \\ E-mail Id: \\ mahak.fas@mriu.edu.in \\ Orcid Id: \\ https://orcid.org/0000-0002-8664-9366 \\ How to cite this article: \\ Sanghi D, Saini P, Mishra P, Sharma M. Outbreaks \\ in India: Impact on Socio-economy and Health. \\ J Commun Dis 2021; 53(1): 35-44. \\ Date of Submission: 2020-10-28 \\ Date of Acceptance: 2021-03-13
}

\section{$\begin{array}{llllllll}\mathbf{A} & \mathbf{B} & \mathbf{S} & \mathbf{T} & \mathbf{R} & \mathbf{A} & \mathbf{C} & \mathbf{T}\end{array}$}

The research activity regarding infectious diseases has been increased significantly in the past few years in India. The main cause of infectious disease is pathogenic microorganisms and the infection can spread from direct or indirect contact between individuals. Once the infection spread throughout the country or world, is classified as an epidemic or pandemic. India is not unfamiliar with pandemic and epidemics, as they occur throughout history. This review paper highlights the major epidemics and pandemic occur in India. More than 90 national and global papers were reviewed. The research papers were chosen from PubMed, Google scholar, science direct, research gate, and organization like WHO. This paper dealt with the impact of pandemic and epidemic on India's economy, health sector and social power. The study concluded that there were around 10 epidemics and pandemics occur in India from the 18 th century to the $21^{\text {st }}$ century. The major impact on the social life and health sector has mainly affected in COVID-19, chikungunya, Plague in India. Meningococcal disease and dengue had a negative impact on health sector. Nipah Virus, plague, and COVID-19 had more impact on tourism. Whereas, economy was majorly affected in Plague, and COVID-19.

Keywords: Infectious Diseases, Social Impact, Pandemic, Epidemic, Communicable Diseases

\section{Introduction}

India is not unfamiliar with pandemic and epidemics. Several pandemics and epidemics occur in India such as influenza, plague, dengue, Nipah virus, zika virus, and many more recorded throughout history. India can eradicate some of the epidemics but still many more diseases prevalent in Indian society and act as a treat to the community. Many researches stated that the major cause of these infections is mainly unhygienic conditions, lack of sanitation, poverty, lack of primary health care facilities, illiteracy, and malnutrition. India is a developing country and facing all these challenges which make India more vulnerable to epidemic and pandemics. ${ }^{1,2}$ According to center and disease control and prevention (2012), ${ }^{3}$ Epidemic is defined as an increased number of cases of infectious disease, as compared to the expected rate of disease in that particular region. The outbreak is defined as the same as an epidemic, the only difference is that it refers to a more limited geographic area. Whereas a pandemic is referred 
to as "an epidemic occurring worldwide, or over a very wide area, crossing international boundaries and usually affecting a large number of people". ${ }^{4}$ The classical definition includes nothing about population immunity, virology, or disease severity.

Both epidemic and pandemic had a severe effect on mortality and morbidity of a country. It leads to high mortality and morbidity in the world. Not only health effects but it also affects the economy - it contributes to the decline of GDP, tourism, trade and the most important social impact means social distancing, closed markets, schools, public services, and lack of physical activity. ${ }^{5}$ The present review paper will highlight all pandemics and epidemics that occurred in India in the past and present and its impact on the economy, health care, social life.

\section{Epidemic and Pandemic in India}

\section{Corona Virus, 2019}

Corona is dangerous killer of current century. A infection from this group should be traced long back in 19 century in Canadian population and infectious is proven among 18 person from 500 which is suspected and have flu like symptoms. ${ }^{6}$ A unknown case of viral pneumonia have been reported in late December 2019, in china whose cause is unidentified and unknown in origin. Center of disease control experts later declared it as group of SARS cov2 and named it as Corona virus. ${ }^{7}$

The outbreak has been traced to sea market of Wuhan where it is suspected to be associated with bats which are basic trading for suspected this living animal market. After this sample of patient were send to specialized lab for diagnosis. ${ }^{8}$ WHO has notified outbreak of virus in China. Human to human transmission have been reported on 11 January China reported its first fatal case. India reported first imported case from which is student from Wuhan city, China on 30 January, 2020 in Kerala. Second case was reported on $2^{\text {nd }}$ February 2020. As of May $5^{\text {th }}, 2020$ MHFW $^{9}$ (Ministry of health and family welfare) has reported more than 46 thousand cases in India with 1600 deaths according to WHO world tally for total no of cases stand at more then 37 lakh infected and 2.5 lakh death and 13 lakh recovered. World Health Organization in January declared that SARSCoV and COVID-19 both are having beta subgroup which was originated from wild bats. ${ }^{10}$ Corona virus is a DNA having following subtypes and many serotypes namely Alpha Beta, Gamma, Delta. ${ }^{11}$

Still the mystery about mode of transmission fact is changing day by day with new researcher. Up till now it is proposed Epidemiologic investigation from epidemic outbreak firstly its association to seafood is identified. Till that time it is considered that person who have visited sea market have got the transmissions. ${ }^{12}$ Later on research have given insight about human to human transmission with largely coughing and sneezing droplet spread is proved to be major source. ${ }^{13}$ Various researchers have proposed droplet infection via surface medium when infected person sneeze or cough secretion transmitted to other person and when they touch there nose or face they get infected. ${ }^{14}$ The joint report of $\mathrm{WHO}$ and China confirms that rate of secondary COVID-19 ranged from 1-5\% among 10,000 close contacts of the confirmed cases in China. Joint report of WHO and China have stated that fecal and oral transmission is not significant in virus spread. ${ }^{15}$

COVID-19 patient are found having symptoms ranging from cough, high fever and fatigue. Patient with dyspnea and diarrhea are also not uncommon. The common symptoms among the patients were fever $(88.7 \%$ when they were hospitalized) and cough (67.8\%). The diarrhea was the uncommon symptom among the patients (3.8\%). In $83.2 \%$ of patients Lymphocytopenia was present. ${ }^{16}$

Incubation period of virus is 14 day she symptoms developed in $2.5 \%$ infected people within 2 days while $97.5 \%$ infected people took 11.5 days to develop the symptoms. The median incubation period was 5.1 days. ${ }^{16}$

Indian government have taken various steps to curb the virus spread in Indian community Indian government started with thermal screening at international airport and also put all international flight at halt. More than 1 million passengers have been screened till now in India in all international airports. Ministry of external affair has shut all the international business to prevent community spread. All non-essential service put to a halt as per government initiative to prevent spread of virus. Economy of all the country has been adversely affected and hit due to the closure of all corporate and factory school. All the developed and developing economy are still under debt due to this versatile virus. COVID-19 hits hard to the global economy. There is a great slowdown in the global economy due to COVID-19 attack which is likely to costs around \$1 trillion.

There is no vaccination available at the present time for the COVID-19. There are only supportive therapy and alternative medicine proposed which are followed by health professionals around the world. The various supportive health therapies include the maintenance of hydration, administration of antipyretic and analgesic and mechanical ventilations is giving as the supportive therapies to the patients. As per now there is no specific treatment for the COVID-19 infection but trial for various antiviruses' drugs and anti-parasitic drug such as lopinavir-ritoanvir and ribavirin are using based on the past experience of the MERS and SARS. There is still lack of literature and research regarding transmission, drug therapy and vaccination for COVID-19. Still further more research is required for COVID-19. 


\section{Nipah Virus}

Nipah viral disease is a zoonotic infection brought about by Nipah infection (NiV), a RNA infection of the variety Henipavirus, family Paramyxoviridae, which is transmitted by specific types of fruit bats, mainly Pteropus spp. ${ }^{17,18}$ and a few other bat animal categories in various nations, including Cambodia, Ghana, Indonesia, Madagascar, the Philippines, and Thailand. Nipah virus outbreaks have been reported in Malaysia, Bangladesh, Singapore and India. Nipah virus triggered a major human outbreak in Malaysia between 1998 to 1999 and is responsible for five subsequent outbreaks in Bangladesh between 2001 and 2005. ${ }^{19,20} \mathrm{NiV}$ was transmitted from pig to humans in Malaysia and Singapore, whereas the cultural practices of consuming date palm sap contaminated by the infected bats in Bangladesh the led to the repeated transmissions.

Three outbreak is reported in India since 2001. First outbreak (2001) was reported in Siliguri (Total 66 cases, 45 deaths), West Bengal, Because Siliguri is in close proximity to Bangladesh. ${ }^{21}$ Second outbreak (2007) in Nadia, West Bengal (30 cases, 5 deaths) and most recently (2018) in Kozhikode district in Kerala. ${ }^{22}$ Episodes, recommended the human-to human transmission, as most people who acquired the disease were either parental figures, or relatives of infected persons. An aggregate of 23 cases were distinguished and 18 laboratory confirmed cases. Twenty cases (87\%) demonstrated respiratory indications and with two survivors case fatality rate was $91 \%$. The infection is liable for causing serious and fast ailment with the respiratory framework as well as the central nervous system (CNS). The signs and indications of the disease seem 3-14 days post NiV introduction. At first, there is a skyscraper of temperature alongside sluggishness and migraine followed by confusion, eventually advancing towards unconsciousness within 1-2 days. ${ }^{23}$

The explanations behind various flare-ups might be low healthcare services framework and absence of a powerful reconnaissance procedure contributes considerably to it.

The outbreak of Nipah virus was limited to few countries, The NiV episode in Malaysia caused a gigantic financial misfortune due to the culling of over 1.1 million pigs to control the outbreak. Studies have indicated that living standards in Malaysia have been lowered largely due to lack of opportunities to work in pig farms. ${ }^{24}$ But free universal health insurance has covered against high medical costs. Household living conditions however, had fallen. Standards had dropped due to limited alternative employment opportunities. In India, epidemic started with direct human contact with bats and consequent nosocomial infection rather than a swine. The span of the outbreak is very small and very less no. of population is affected with the virus, so it doesn't affect the Indian economy lot.

\section{Zika Virus}

The first reported Zika virus (ZIKV) outbreak in the Marquesas Islands in $2013^{25}$ and after wards spread to Brazil in $2015^{26}$, health departments in India were also on alert. It was anticipated that a ZIKV outbreak in India was possible due to the presence of the Aedes aegypti mosquitoes. Zika Virus (ZIKV) became a public health and disease threat in early 2016 (WHO 2016a). According to the WHO, the virus has been reported in over 69 countries and territories worldwide, with the highest concentration of cases in Latin American and Caribbean countries (LCR) (WHO 2016b) as of 10 August 2016.

In Ahmedabad, Gujarat, India, 3 laboratory confirmed cases of ZIKA disease were reported by "Ministry of Health and Family Welfare, Government of India" in 2017. ${ }^{27}$ The cases were tested and confirmed by "real-time reverse transcription polymerase chain reaction (RT-PCR)" test. The most recent cases of Zika virus are a big cause for concern in India.

In late 2018, 159 cases of Zika virus infection were registered in Rajasthan and 127 in Madhya Pradesh. ${ }^{28,29}$ Because most Zika virus infections are mild or asymptomatic, the magnitude of these flare-ups is likely disparaged, and the impact could be serious if the example proceeds into 2019. The enormous populace and across the board neediness in India make uncontrolled spread of Zika infection likely. ${ }^{30}$

ZIKV is primarily transmitted through mosquito bites but in 2016, sexual contact transmission was recorded from time to time in at least 11 non endemic countries including France, Italy, Germany, Spain, Portugal, New Zealand, United States of America, Canada, Argentina, Chile and Peru. ${ }^{27}$ It is associated with neurological complications: Guillain-Barré syndrome and microcephaly in infants born to pregnant women infected with the virus.

Zika epidemic had long-term and short term impact in Latin America and Caribbean. In the short term, the expanses was around $\$ 1$ billion on average for every $5 \%$ rise in infection incidence Microcephaly and Guillain-Barré syndrome are associated with the highest term costs, with the overall expanses theoretically exceeding $\$ 8$ billion for microcephaly cases and \$3 billion for Guillain-Barré syndrome cases in the world. ${ }^{31}$ The most significant portion is the lost earnings of microcephalus people who may not be able to join the labor force. The effect on the poorest countries is severe, which are predicted to lose 1.13 (Haiti) and 1.19 (Belize) percent of GDP annually (in the high Zika scenario). Rapid urbanization with favorable conditions for the vector altogether increases the risk of transmitting Zika virus. Zika had negative impact on multiple SDGs, including SDG 1 on poverty eradication, SDG 3 on good health and wellbeing and SDG 5 on gender equality and women's empowerment. 
The Word Bank underscores that economies of nations that rely fundamentally upon the travel industry could definitely experience the ill effects of the ZIKV spread, and the drop in their GDP can arrive at $1.6 \%$ in view of the diminishing the travel industry. As less populace of India is influenced so it didn't have huge effect on Indian economy.

\section{Influenza}

From century infectious diseases has emerged as major health concerns, with much infectious disease arising in this century. Avian influenza has been reported as deadly infectious disease. There are various strain of this influenza virus which is responsible for various disease in human, dog etc. Influenza virus type A (H5N1) is a highly infectious species of virus mainly affecting poultry bird species. There are various forms of influenza and classified are according to their surface proteiniehemagglutinin (HA) and Neuraminidase (NA). Examples include many type of influenza strain like "bird flu" virus subtypes A (H5N1, H9N2) or swine influenza "swine flu" virus subtypes A (H1N1, H3N2). All of this animal influenza type A have a distinct viruses are distinct characteristic that human to human transmission is very less or not reported. Birds are considered to be main reservoir with Aquatic and poultry birds are primary and natural reservoir for influenza. Virus can also be classified as highly pathogenic and low pathogenic according of severity of disease they cause in poultry. ${ }^{32}$ Incubation period of the disease is exposure period to suspected illness. Incubation period is of 7 days or more after the last exposure to sick or dead poultry.

Avian influenza infection symptoms include disease mild symptoms from upper respiratory tract infection to severe symptoms like pneumonia or respiratory failure in many patients infected by avian influenza viruses, the disease has an aggressive clinical course with high grade fever lower respiratory tract infection and breathlessness. Complications related to virus can range anywhere between pneumonia respiratory failure and septic shock. Attention toward this disease have been focused from 1997 when human infection and six fatality have been reported by this virus in Hong Kong. ${ }^{33}$ Pandemic quality of the virus has also been realized during this only period.

\section{Avian Influenza Outbreak (2003-2004)}

Outbreak of avian influenza has been observed in year 2003 again when WHO reported Asian, European and African countries have reported a 526 human infections with 311 fatalities. ${ }^{32}$ Alarming outbreak of avian influenza occurred in year 2003 among member of family who travelled from province of china and death of child and person is reported with other remained unidentified. ${ }^{34}$

Outbreak again reported in February 2003, When 89 people are confirmed positive in which 78 have conjunctivitis and 5 cases have respiratory illness and one reported death. ${ }^{34}$
Following this incidence in December 2003 and January 2004 Korea and Japan reported epidemic In December 2003 a large number of chicken are diagnosed with this mortal disease. Various research have given insight that in March 2004, as many as from Vietnam and Thailand 23 and 16 death are reported respectively and 12 from Thailand with 8 deaths. By mid-March 2004, no countries other than Thailand and Vietnam had reported human cases. According to WHO during 2011, 49 cases are reported from various countries with 25 deaths.

Recently according to WHO report ${ }^{35}$ on 26 march 2020 between 20 and 26 March 2020, there is no human to human and no bird to infection are reported. Four western pacific countries have reported total of 238 human infections with A (H5N1), since January 2003. Of total reported cases 134 were succumbed to death resulting in a case fatality rate (CFR) of 56\%. China has reported last case on 27 December 2015 (one case, no death). Global stats for period of 17 years (January 2003 to 26 March 2020), there were total 861 reported human infection with avian influenza $A$ (H5N1) virus reported from 17 countries across the globe. Of these total infections across the country during this period 455 person were deceased (CFR of 53\%). Last reported case across the globe is on 30 April 2019 from Nepal.

Indian statics for the avian influenza according to Department of Animal Husbandry has reported from 15 States and Union Territory across India 25 episodes of AI A (H5N1) is reported poultry birds. First reported outbreak was reported by state of Maharashtra and Gujarat in February 2006. From three year from 2011 the outbreak of highly pathogenic avian influenza has been reported. "During 2011-2012 and 2012-2013 outbreaks of highly pathogenic avian influenza (HPAI) were detected in crows in several states of India". But the impact of avian influenza has been mild in India and not many cases reported.

Economy has been damaged by avian flu where infected countries have suffered a reduction in international tourism and thus it has consequently affected sectors like transportation hotel and retail sales. This epidemic have not produced much effect on economy as other epidemic and pandemic do.

As the human episode of disease is less, so it has not adversely affected health care system and economy as a whole

\section{Chikungunya}

Chikungunya is a vector borne disease. It is disease caused by chikungunya virus Chikungunya virus (CHIKV) is identified as positive stranded enveloped RNA virus belonging to genus Alphavirus of the family Togaviridae. ${ }^{36}$ Chikungunya virus (CHIKV) in humans are transmitted by Aedes mosquoite. ${ }^{37}$ The outbreak of the diseases occurred 
between 1952 to 1953 worldwide and first reported from patient in Tanzania and some parts of Africa also affected by the disease. First case from Asia has been traced from Thailand in 1958. African and Asian country remains highly affected by the disease affecting public life. ${ }^{38}$

India is also affected by the disease every two to three decades since $1960 .^{39}$

Calcutta city in 1963 has first reported outbreak of chikungunya. This disease occurred in pandemic form in year 2006 which result in huge disability and major life concern. ${ }^{39,40}$ Chikungunya is characterized by fever, headache, rashes, and debilitating arthralgia. And is believed to be a non-fatal and self-limiting, but a modified and severe form of disease recently reported with CNS involvement and fulminant hepatitis has been reported on the Indian Ocean island of Réunion By March, 2006, a third of the population was affected and the disease had caused 237 deaths. ${ }^{41}$ The virus has resurged in December 2005 and according to official parameters 1391165 suspected virus cases are reported National Vector borne Disease Control Programme. ${ }^{42}$ According to researchers WHO have not played a major role in managing this chikungunya epidemic in India. As there is no information about chikungunya epidemic in India. There is March 24, 2006, and a report on the WHO website from Oct 17, 2006, which both describe chikungunya and dengue epidemics in the Indian Ocean islands and India. ${ }^{43,44}$

The haematophagus arthropods bite is the major source of spread of virus to other animals and humans. There are various species of various found responsible for the disease in humans are Bunyaviridae, Togaviridae, Flaviviridae, Reoviridae and Rhabdoviridae. ${ }^{45}$ After the exposure or bite of arthropod virus enter skin and blood stream and it replicate in dermis and fibroblast and spreads to various organs including spleen, lymph nodes muscles, and joints. The period between infection and clinical manifestation can be two to ten days. ${ }^{46}$ Clinical symptoms may manifest as milder to severe to asymptomatic Various diagnostic technique can be used sample is collected and detected on eight day of infection and virus isolation is done. Rapid testing is sensitive and rapid method for disease before seventh day for the early diagnosis of this infection, particularly in cases of meningoencephalitis and vesiculobullous dermatitis in newborns.

Several drugs are known to be effective against CHIKV when tested in vitro, but no recognized antiviral treatment is currently available. It has a global impact on economy of all developing and developed country. The resurgence of disease has a devastation effect on already overburdened health care system in developing and thus there is extensive research going on with the aim to develop newer strategies to tackle this medical menace to humanity.

\section{Japanese Encephalitis (JE)}

Japanese encephalitis (JE) is a vector borne disease and spread by mosquito. It is the disease is caused by flaviviral. In the disease occurs with the symptoms may include vomiting, fever, severe headache and inflammation of brain. JE Impacted worldwide, mostly prevalent in eastern and southern Asia. According to WHO the occurrence of JEV disease in various countries with a range from 1 to 10 cases in every 1 lakh populations. The diseases are responsible for almost 68,000 cases yearly throughout the world. The disease mainly spread in rural areas by mosquitoes breed at rural haat and areas of piggery farm. The mosquito's species from genus Culex is responsible for spreading the JE disease and the susceptible reservoir hosts of JE is pigs, birds, bats. During rainy season in Southeast Asia rate of transmission was high, however, and in case tropical regions it happened throughout the year. The infections of JE spread from pigs easily and virus gets opportunity to pick up due to prolonged viraemia. ${ }^{47}$

\section{Outbreaks 1952-1995}

First cases of Japanese Encephalitis (JE) in India have been reported since the year 1955 . JE outbreaks marked increase due to vector density during the monsoons and postmonsoon period. However, the studies conducted in 1952 revealed that JEV in India reported many regions. The occurrence of this disease in India was mainly reported in two time i.e. April to July and September to December. Bankura district of West Bengal State was the major outbreak for JE in the year $1973 .{ }^{48}$

The cases of JE reported in every part of India mostly Southern states Andhra Pradesh, Karnataka, Tamilnadu and Kerala North East States namely Assam and Manipur also Eastern states namely Bihar, Orissa, West Bengal whereas Northern states namely Haryana, Uttar Pradesh. The disease was also reported in UTs of Goa and Pondicherry throughout the year. From the year 1978, activity of the JE disease constantly monitored in the state of Uttar Pradesh. In the year 1990, the state of Haryana reported the first case of JE. The number of cases gradually increases in the state. In Bihar, Muzaffarpur district reported the first case in the year 1995 as most of the children suffering from an unexplained acute neurologic illness due to high temperature and also due to the exposure of pesticides. ${ }^{49}$

\section{Outbreaks in 2005- 2016}

In the year 2005 between July and November Gorakhpur district, UP reported longest epidemic of viral encephalitis. Total number of cases 5,737 in which 1,344 persons died due to JE disease the state of Eastern Uttar Pradesh mainly in 7 districts i.e. Gorakhpur and Basti divisions of Uttar Pradesh found promotive to spread this virus due to annual flooding. ${ }^{50}$ The virus in India witnessed another 
large outbreak in found active in northern and northeastern states i.e. Manipur in July 2016.

Government of India prepared strategy to control the disease burden and also to prevent the death rate. Vector Control Management initiated by Gol started surveillance programs by providing vaccination services to areas affected by this disease. The advisories were issues relating to sanitation, safe drinking water etc and also provided technical support on overall health and social rehabilitation to overcome from JE. ${ }^{51}$

\section{Meningococcal Disease}

Meningococcal disease caused by meningococcus (Neisseria meningitidis) and outbreak was reported in the year 1805 in Geneva as bacterial diseases. The disease shaped like coffee bean bacteria seen in pairs. The common symptoms seen in this disease are fever, severe headache, nausea and vomiting etc. Due to the nature of this disease as invasive it was difficult to control. The clinical symptoms including septicemia. Joints of bone also affected..$^{52}$

It can live in nasopharynx in $10 \%$ of population. ${ }^{53}$ The bacteria are mainly transmitted by air and direct contact with body such as kissing. ${ }^{54}$

The disease was spread in both ways through virulence of the strain and the susceptibility of the host due to invasive and carriage of this disease. ${ }^{53,54}$ Meningococcal is life-threatening disease resulting death and disability. ${ }^{55,56}$

\section{Outbreaks from 1985 to 1989}

In the year 1985 in Delhi NCR region Meningococcal cases 6133 reported with 799 deaths. The State of Gujarat mainly in district of Surat has been reported 197 cases and 34 deaths in the year 1985-87. State of Andhra Pradesh reported 475 cases and 108 deaths in the year 1989. During the year 1989 State of Odisha reported 2951 cases and 344 deaths and State of Madhya Pradesh reported 250 cases and 75 deaths. ${ }^{57}$

\section{Outbreaks from 1996 to 2009}

Outbreaks of this disease were also reported in the year 1996 in Delhi with 616 cases. Occurrence of disease in the year 2005, 2006, 2007 and 2008 in the state of Delhi, were reported as 527 cases, 867 cases, 380 cases and 393 cases respectively. The cases of disease increases in every yearly. The cases were also found in the year of 2009 as 85 cases.

During the 2008-09 the state of Meghalaya reported 2100 cases and 260 deaths. The State of Tripura reported 277 cases and 60 deaths. Adolescents and young adults were affected mostly due to this disease. ${ }^{58}$

An experts group at national level has been established by the national authorities for coordination to provide support to investigate, adaptation and preparation of guidelines and also to monitor the activity regularly about the situation of disease also to prepare strategies. The group is comprised of Ministry of Health \& Family Welfare, Gol, Statuary bodies of State Government and Central Government were worked together.

\section{Dengue}

The disease is endemic affected most serious in most of the countries. It is viral disease transmitted by mosquito bite of Aedes Aegypti. The incubation period of the disease 5-6 days after being bitten by mosquito. This disease has classified in two forms Dengue Fever symptoms as Flue like illness and severe form of disease. There are several mode of transmission of disease categories in different modes such as Mosquito-to-human in which the disease transmitted to humans through the bites of infected female mosquitoes, primarily the Aedes aegypti mosquito and Human-to-mosquito in which the Mosquitoes can become infected from person who are infected with dengue. In this disease no symptoms shown in infected person and third mode of transmission is mother to child during pregnancy. ${ }^{59}$

Coconut shells, coolers, stored fresh water, empty containers, bottles, water logged places flower pots, tanks and many more places where rainwater collects or is stored. In this case the female mosquito laid her eggs and eggs can remain live for months, and mainly active with water. Symptoms of dengue fever reported as difficulty in breathing severe continuous stomachache, yellow skin, cold and also the symptoms of dysphasia etc.

The first outbreak was reported in Madras (now Chennai) in the year of 1780 and during the year 1963-1964 reported in Calcutta and Eastern Coast of India. ${ }^{60-62}$ As per the study reported that India prevailing mostly in urban areas around 33 lakhs (34\%) infections as global threat. ${ }^{60}$

\section{Outbreaks in 2012 to 2019}

According to Health Ministry Gol, during the year 2012 (January- October) total of 55,000 cases and 138 Indian people died. The cases range from 4000 to 15000 and approximate 9-60 deaths reported in states namely Karnataka, Delhi, Kerala, Punjab, Gujrat, and Haryana during the year 2015. As per the National Vector Borne Disease Control Programme ${ }^{63}$ reported based on the data taken from different medical colleges in India that around 5,778,406 cases annual average diagnosed clinically recorded across the country due to dengue virus. According to National Vector Borne Disease Control Programme, ${ }^{63}$ North East State namely Arunachal Pradesh, State of Haryana, Punjab and Uttar Pradesh data showed that there was increase in number of cases of dengue during the year 2015 compared to the previous years.

In the year 2019, the total no. of cases reported in India 136422 cases and 132 deaths, in which the states of 
Maharashtra reported 12374 cases and 25 deaths whereas, the State of Karnataka reported as highest number 15232 case and 13 deaths. ${ }^{64}$

\section{SARS}

Sever Acute Respiratory Syndrome was emerged as a readily transmissible new disease of respiratory illness in $21^{\text {st }}$ century. ${ }^{65}$ SARS-CoV is an animal virus from an uncertain animal reservoir, might be bats, which spread to other animals (civet cats). It was first time infected to a human in Southern Chinese province of Guangdong and then spread quickly to Hong Kong and followed to other countries like Taiwan, Singapore, Vietnam, Canada, USA and UK. ${ }^{66,67}$ The causative agent of SARS CoV, caused unusual symptoms of respiratory infection and severe form of pneumonia, high fever, >38 degree centigrade/104 Fahrenheit, coughing, breathing difficulty, diarrhea (20\% cases), malaise, myalgia and headache. ${ }^{67} \mathrm{~A}$ report of total 8098 cases, from November, 1, 2002 to July, 31, 2003 were stated by World Health Education. ${ }^{68,69}$ In India, out of 10 suspected cases only three were reported with SARS. An epidemic of SARS affected 26 countries and resulted in more than 8000 cases and 774 deaths in 2003. 67,70 WHO's estimated the case fatality ratio as $14-15 \%$ but in individuals more than 65 years, it exceed to $50 \%$. SARS CoV spreads mainly through close person-to - person contact via coughing or sneezing done by an infected person. The incubation period was not longer than 10 days. ${ }^{67}$ The SARS CoV doesn't have tendency to survive in hot weather - higher the temperature, lesser the lifespan of the virus (not more than 4 hours outside the human body) but in stools of the infected person with the symptoms of diarrhea, it usually survive for around 4 days. ${ }^{66,67}$

SARS had a larger impact on the health of public health care workers of local health care systems. They were infected during the epidemic and were needed more intensive care and hospital health care facilities. This condition leads to affect the well-being of many health care professional and due to excess of caretaker demands of infected individual, put apparently healthy public health care professional on risk and decreased the capacity of them to fight against disease. Keeping in mind the economic effects of SARS, has a drastic effect on Asia. Economic costs during an epidemic is estimated by disease-associated medical costs, need to maintain sterile environment, preventive measure implementation, evidence based research and by diseaserelated morbidity and mortality. However, SARS had less economy impact as compared to major epidemics such as HIV/ AIDS, tuberculosis and malaria.

However, there was no major impact on India in relation to health care system, society and economy because of only few cases were reported in India.

\section{Plague}

Plague has a high mortality rate without treatment as it is a bacterial infectious disease. Since $6^{\text {th }}$ century, there were major three epidemics of plague emerged. A gramnegative, immobile, non-spore-forming coccobacillus entitled as Yersinia pestis is a considered as a causative agent of plague. ${ }^{71,72}$ The incubation period of plague is not more than 6 days. It usually transmitted from rodent to rodent by fleas' vectors and from animals to human being by infected fleas bite, direct contact, inhalation of airborne flea excrement and rarely, consumption of infective materials infected by the host. ${ }^{73}$ Yersinia pestis infections can majorly occur in 3 clinical forms in homo sapien - bubonic plague, primary septicaemic plague and primary pneumonic plague. ${ }^{74}$ In India majorly the plague is bubonia. The primary septicaemic plague usually occur because of accidental laboratory infections, not very common in India and the pneumonic plague is also very rare, ${ }^{75}$ but if exist it usually confined to some families only, doesn't spread rapidly. Less that $1 \%$ of Indian population suffers from pneumonic plague and since, 1895 the incidence was not more than three percent. ${ }^{76}$ A research published in 'Nature' (1938) stated that it's mainly field rats which were responsible for spreading of the plague epidemic not house rats. The climatic condition also prevent the spread of plague in my regions of India, for instance heavy annual flood in Bengal, dearth of fleas in Madras and Assam. ${ }^{76}$

\section{Plague Epidemic, 1994}

The outbreak of plague was first reported in Maharashtra state, Mamla Village (Beed district) and in Gujarat (district Surat). In Mamla village, the outbreak was Bubonic plague with the symptoms of headache, chilliness, acute high fever, malaise and pain in the affected regional lymph nodes. ${ }^{72-74}$ The incubation period was 2-10 days. Bite of infective fleas was the major cause. By September 1994, almost $10 \%$ people of Mamla village developed these symptoms. ${ }^{77} 596$ speculative cases were reported. ${ }^{78}$

On the other hand at similar time another outbreak of plague was emerged in Surat district. It was a Pneumonic plague with the symptoms of high fever and shivering, headache, cramping of muscles, severe malaise, muscular pains. ${ }^{71}$ If remain untreated symptoms like dyspnea, coughing with blood sputum and further affects lungs and might cause bronchopneumonia with the incubation period was 1-6 days. 146 speculative cases and 54 deaths were reported. ${ }^{78}$

A researcher did a case study on outbreak in India in 1994, stated that the impact of plague epidemic on economy of India was huge. In Gujrat alone the financial loss was predicted to be around US\$ 260 million. Export of agricultural goods were also affected as some of the countries like UAE refused to import 5 lakhs of fresh fruits 
at that time. Tourism industry was also had a setback as many foreign travelers stoled their trip to India.

\section{Plague Epidemic 2002}

Another pneumonic plague hit India in February 2002 at Hat Koti village, Shimla district, and Himachal Pradesh state. 16 cases and 4 deaths were reported. ${ }^{74,78} \mathrm{~A}$ study conducted by Goel ${ }^{80}$ studied socio-epidemiological determinants of plague, 2020. He stated that one of the major cause of spreading of disease was lifestyle behaviors of the individuals like lack of hygienic practices, more members in small house, refuse to take medical help because they believe in God - means god will same them and hunting behavior of the human being.

\section{Plague Epidemic 2004}

Another outbreak was reported in India on 2004, it was a bubonic plague at Dangud village, Uttar Kashi district, and Uttarakhand state. But it came in control within 2 weeks. Only 8 speculative cases were identified and 3 deaths reported. ${ }^{81}$

\section{Conclusion}

The study concluded that there were around 10 epidemics and pandemics occur in India from the 18th century to the $21^{\text {st }}$ century. The major impact on the social life and health sector has mainly happened in COVID-19, chikungunya, Plague in India. Meningococcal disease and dengue had a negative impact on the health sector. Nipah Virus, plague, and COVID-19 had more impact on tourism. Whereas, regarding economy major negative impact was seen in Plague, and COVID-19. Diseases such as Nipah Virus, Zika Virus, Avian influenza, Chikungunya, Plague, Sever Acute Respiratory Syndrome (SARS), Meningococcal and Cholera there are no reports on the impact of poverty and socio economic as very few cases reported in India. Whereas the high prevalence diseases such as Dengue, Japanese Encephalitis (JE), COVID-19 impacted most of the sectors resulting the slow down the economy of the country. The illness due to the epidemics diseases researches revealed high impact on socio-economic of the families suffering from the disease. Poor accessibility of health care facilities at village level and also to transportation issues from village to cities for their health rehabilitative services. As seen above, an outbreak of diseases have shown the potential impact in several sectors of the country's economy also damage. Most of the researches advocate that there is need to improve the surveillance system to predict the cause symptoms and control measures of the disease and investment in health sector.

\section{Conflicts of Interest: None}

\section{References}

1. Rice $A L$, Sacco $L$, Hyder $A$ et al. Malnutrition as an underlying cause of childhood deaths associated with infectious diseases in developing countries. Bulletin of the World Health Organization 2000; 78: 1207-21.

2. John TJ, Dandona L, Sharma VP et al. Continuing challenge of infectious diseases in India. The Lancet 2015; 377(9761): 252-69.

3. Center and Disease Control and Prevention. 2012. Available from: https://www.cdc.gov/csels/dsepd/ ss1978/lesson1/section11.html.

4. Last JM. A dictionary of epidemiology. $4^{\text {th }}$ edition. Oxford University Press, New York. 2001.

5. Qui W, Chu C, Mao A et al. The impact on health, society and economy of SARS and H7H9 outbreak in China: A case Comparison Study. Journal of Environment and Public Health 2018: 1-7.

6. Kumar D, Malviya R, Kumar Sharma P. Corona virus: a review of COVID-19. EJMO 2020; 4(1): 8-25.

7. Huang C, Wang Y, Li X, et al. Clinical features of patients infected with 2019 novel coronavirus in Wuhan, China. Lancet (London, England) 2020; 395: 497-506.

8. Holshue $\mathrm{ML}$, DeBolt $\mathrm{C}$, Lindquist $\mathrm{S}$, et al. First case of 2019 novel coronavirus in the United States. New England Journal of Medicine 2020; 382(10): 929-36.

9. Ministry of family welfare, government of India, current status of COVID-19. 2020. Available from: https://www. mohfw.gov.in/.

10. World Health Organization. Director-General's opening remarks at the media briefing on COVID-19. 2020. Available from: https://www.who.int/dg/speeches/ detail/who-director-general-s-opening-remarks-atthemedia-briefing-on-covid-19---24-february-2020.

11. Woo PC, Lau SK, Tsoi HW et al. Clinical and molecular epidemiological features of coronavirus HKU1associated community-acquired pneumonia. The Journal of Infectious Disease 2005; 192(11): 1898-907.

12. Pung R, Chiew CJ, Young BE et al. Investigation of three clusters of COVID-19 in Singapore: implications for surveillance and response measures. The Lancet 2020; 395: 1039-1046.

13. Yuan $\mathrm{H}, \mathrm{Cao} X, \mathrm{Ji} X$ et al. Current emerging respiratory infection: epidemiological and clinical characteristics, diagnosis and treatments of COVID-19. SSRN 2020; 80(6): 656-665.

14. Goh GKM, Dunker AK, Foster JA et al. Rigidity of the outer shell predicted by a protein intrinsic disorder model sheds light on the COVID-19 (Wuhan-2019-nCoV) infectivity. Biomolecules 2020; 10(2): 331.

15. Report of the WHO-China Joint Mission on Coronavirus Disease 2019 (COVID-2019). February 16-24, 2020. http://www.who.int/docs/default-source/coronaviruse/ who-china-joint-mission-on-covid-19-finalreport.pdf (Accessed on March 04, 2020).

16. Guan WJ, Ni ZY, Hu Y et al. Clinical characteristics of 
coronavirus disease 2019 in China. New England Journal of Medicine 2020; 382: 1708-1720.

17. Halpin K, Young PL, Field HE et al. Isolation of Hendra virus from pteropid bats: a natural reservoir of Hendra virus. J Gen Virol 2000; 81(Pt 8): 1927-1932.

18. Vandali V, Biradar RB. Nipah virus (NiV) infection: a systematic review. JOJ Nursing \& Health Care 2018; 8(1): 555729.

19. Chua KB, Bellini WJ, Rota PA et al. Nipah virus: a recently emergent deadly paramyxovirus. Science 2000; 288: 1432-5.

20. Murray K, Selleck P, Hooper P, et al. A morbillivirus that caused fatal disease in horses and humans. Science 1995, 268: 94-97.

21. Chadha MS, Comer JA, Lowe L et al. Nipah virusassociated encephalitis outbreak, Siliguri, India. Emerg Infect Dis 2006; 12(2): 235-240.

22. Chatterjee P. Nipah virus outbreak in India. Lancet 2018; 391(10136): 2200.

23. Hossain MJ, Gurley ES, Montgomery JM et al. Clinical presentation of Nipah virus infection in Bangladesh. Clin Infect Dis 2008; 46(7): 977-984.

24. Ng CW, Choo WY, Chong HT et al. Long-term socioeconomic impact of the Nipah Virus encephalitis outbreak in Bukit Pelanduk, Negeri Sembilan, Malaysia: a mixed methods approach. Neurol Asia 2009; 14(2): 101-107.

25. Roth A, Mercier A, Lepers C et al. Concurrent outbreaks of dengue, chikungunya and Zika virus infections - an unprecedented epidemic wave of mosquito-borne viruses in the Pacific 2012-2014. Euro Surveill 2014; 19: 20929.

26. Pan American Health Organization, World Health Organization, Regional Office for the Americas. Increase of microcephaly in the northeast of Brazil. Epidemiological Alert 2015. Available from: http://www.paho.org/hq/index.php?option=com_ docman\&task=doc_view\&Itemid=270\&=en.

27. Zika Virus Infection - India. Disease Outbreak News. 2017. Available from: http://www.who.int/csr/don/26may-2017-zika-ind/en/.

28. Yadav PD, Malhotra B, Sapkal G et al. Zika virus outbreak in Rajasthan, India in 2018 was caused by a virus endemic to Asia. Infect Genet Evol 2019; 69: 199-202.

29. Saxena SK, Kumar S, Sharma R et al. Zika virus disease in India - update October 2018. Travel Med Infect Dis 2019; 27: 121-122.

30. Vijaykumar S, Raamkumar AS. Zika reveals India's risk communication challenges and needs. Indian J Med Ethics 2018; 3: 240-4.

31. Honeycutt AA, Grosse SD, Dunlap $\amalg$ et al. Economic costs of mental retardation, cerebral palsy, hearing loss, and vision impairment. Research in Social Science and
Disability 2018; 3: 207-28.

32. World Health Organization. Cumulative Number of Confirmed Human Cases of Avian Influenza A/(H5N1) Reported to WHO. 2011. Available from: http://www. who.int/csr/disease/avian_influenza/country/cases_ table_2011_03_02/en/index.html.

33. De Jong JC, Claas EC, Osterhaus AD et al. A pandemic warning? Nature 1997; 389(6651): 554.

34. Barror S. Recent Avian Influenza Outbreaks: A Pandemic in the Waiting. Journal of Microbiology 2005; 23: 72-3.

35. World Health Organization. Cumulative number of confirmed human cases of avian influenza A (H5N1) reported to WHO. 2020.

36. Gudo ES, Black JF, Cliff JL. Chikungunya in Mozambique: a forgotten history. PLoS Negl Trop Dis 2016; 1710(11): e0005001.

37. Robinson MC. An epidemic of virus disease in Southern Province, Tanganyika Territory, in 1952-53. I. Clinical features. Trans R Soc Trop Med Hyg 1955; 49(1): 28-32.

38. Schwartz O, Albert ML. Biology and Pathogenesis of Chikungunya virus. Nat Rev Microbiol 2010; 8: 491-500.

39. Staples JE, Breiman RF, Powers MA. Chikungunya fever: An epidemiological review of a re-emerging infectious disease. Clin Infect Dis 2009; 49: 942-8.

40. Mavalankar D, Shastri P, Raman P. Chikungunya epidemic in India: a major public-health disaster. Lancet Infect Dis 2007; 7: 306-7.

41. Bonn D. How did chikungunya reach the Indian Ocean? Lancet 2006; 6: 543.

42. National Vector borne Disease Control Programme. Chikungunya fever situation in the country during 2006. 2007. Available from: http://namp.gov.in/Chikun-cases. html.

43. World Health Organization. Outbreak news. Chikungunya and dengue, south-west Indian Ocean. Wkly Epidemiol Rec 2006; 81: 106-9.

44. World Health Organization. Chikungunya in India. World Health Organization, Geneva. 2006. Available from: http://www.who.int/csr/don/2006_10_17/en/index. html.

45. Lopes N, Nozawa C. Característicasgerais e epidemiologia dos arbovírusemergentes no Brasil. Rev PanAmazSaude 2014; 5(3): 55-64.

46. Kam YW, Ong EK, Rénia L et al. Immuno-biology of chikungunya and implications for disease intervention. Microbes Infect 2009; 11(14-15): 11861196.

47. Kulkarni R, Gajanan NS, Kaushal H et al. Japanese encephalitis: a brief review on Indian perspectives. Open Virology Journal 2018; 12: 121-130.

48. Parida M, Dash PK, Tripathi NK et al. Japanese Encephalitis Outbreak, India, 2005. Emerg Infect Dis 2006; 12(9): 1427-1430. 
49. Sarkar A, Taraphdar D, Mukhopadhyay SK et al. Molecular evidence for the occurrence of Japanese encephalitis virus genotype I and III infection associated with acute encephalitis in patients of West Bengal, India, 2010. Virol J 2012; 9(1): 271.

50. Rathi AK, Kushwaha KP, Singh YD et al. JE virus encephalitis: 1988 epidemic at Gorakhpur. Indian Pediatr 1993; 30(3): 325-333.

51. Saxena V, Dhole TN. Preventive strategies for frequent outbreaks of Japanese encephalitis in Northern India. $J$ Biosci 2008; 33(4): 505-514.

52. Sinclair D, Preziosi M, John TJ et al. The epidemiology of meningococcal disease in India. Trop Med Int Health 2010; 15(12): 1421-1435.

53. Yazdankhah SP, Caugant DA. Neisseria meningitides: an overview of the carriage state. Journal of Medical Microbiology 2004; 53: 821-832.

54. Stephens DS. Uncloaking the meningococcus: dynamics of carriage and disease. The Lancet 1999; 353: 941-942.

55. Schwartz B, Moore PS, Broome CV. Global epidemiology of meningococcal disease. Clinical Microbiological Review 1989; 2: S118-24.

56. Rosenstein NE, Perkins BA, Stephens DS et al. Meningococcal disease. New England Journal of Medicine 2004; 344: 1378-1388.

57. Singhi S, Jain V, Gupta G. Pediatric emergencies at a tertiary care hospital in India. Journal of Tropical Pediatrics 2003; 49: 207-11.

58. Kumar S, Kashyap B, Bhalla. The rise and fall of epidemic Neisseria meningitides from a tertiary care hospital in Delhi, January 2005-June 2007. Tropical Doctor 2008; 38: 222-4.

59. Duong V. Asymptomatic humans transmit dengue virus to mosquitoes. Proceedings of the National Academy of Sciences of the USA 2015; 112(47): 14688-93.

60. Sarkar JK, Chatterjee SN, Chakravarty SK. Haemorrhagic fever in Calcutta: some epidemiological observations. Indian J Med Res 1964; 52: 651-659.

61. Chatterjee SN, Chakravarti SK, Mitra AC et al. Virological investigation of cases with neurological complications during the outbreak of haemorrhagic fever in Calcutta. J Indian Med Assoc 1965; 45: 314-316.

62. Carey DE, Myers RM, Reuben R et al. Studies on dengue in Vellore, South India. Am J Trop Med Hyg 1966; 15: 580-587.

63. Gupta N, Srivastava S, Jain A et al. Dengue in India. Indian Journal of Medical Research 2012; 136(3): 373-390.

64. Dayaraj C, Kakade MB, Bhagat AB et al. Detection of dengue-4 virus in Pune, western India after an absence of 30 years - its association with two severe cases. Virol J 2011; 8: 46-49.

65. World Health Organization. Summary of probable SARS cases with onset of illness from 01 November 2002 to
31 July 2003. 2004. Available from: http://www.who. int/csr/sars.html.

66. Mehta SK, Sashindran VK, Kumar K et al. Severe acute respiratory syndrome: an update. MJAFI 2007; 63: 52-5.

67. World Health Organization. SARS (Severe Acute Respiratory Syndrome). 2020. Available from: https:// www.who.int/ith/diseases/sars/en/.

68. World Health Organization. Prevention and Control of Severe Acute Respiratory Syndrome (SARS). $21^{\text {st }}$ Meeting of Ministers of Health New Delhi, India. 2003.

69. Chang YM, Yu WC. Outbreak of severe acute respiratory syndrome in Hong Kong special administrative region: case report. BMJ 2003; 326: 850-852.

70. Thomas PA. Severe acute respiratory syndrome (SARS): A bolt from the blue. Indian Journal of Medical Microbiology 2003; 21(3): 150-151.

71. Zietz $P$, Dunkelberg $H$. The history of plague and the research on causative agent Yersinia pestis. International Journal of Hygiene and Environmental Health 2004; 207: 165-178.

72. Perry RD, Fetherston, JD. Yersinia pestis - etiologic agent of plague. Clin Microbiol Rev 1997; 10: 35.

73. National Health Portal of India. 2016. Available from: https://www.nhp.gov.in/disease/communicabledisease/plague.

74. World Health Organization. Plague in India. 2002. Available from: https://www.who.int/csr/don/ 2002_02_20/en/.

75. Seal SC, Bhatiacharji LM. Epidemiological studies on plague in India. Part II. The role of movement of rats in the spread of plague infection (with special reference to the epidemiology of plague in Calcutta, 1948-51). Indian Med Res 1961b; 49: 997-1007.

76. Seal SC. Epidemiological studies of plague in India. Bull Org Mond Sante 1969; 23: 283-292.

77. Judith BT. Plague in India-1994: Conditions, Containment, Goals. Available from: http://www.wastetohealth.com/ plague_in_india_1994.html.

78. Clem A, Galwankar S. Plague: A decade since the 1994 outbreaks in India. JAPI 2005; 53.

79. The plague outbreak in India in 1994-A case study. Dealing with biological outbreaks: a case study of the plague (1994) and dengue. Available from: https://shodhganga. inflibnet.ac.in/bitstream/10603/78199/10/09_ chapter\%206.pdf.

80. Goel S, Kaur H, Gupta AK et al. Socio-epidemiological determinants - 2002 plague outbreak in Himachal Pradesh, India: a qualitative study. BMC Public Health 2014; 14: 325.

81. Mittal V, Rana UV, Jain SK et al. Quick control of bubonic plague outbreak in Uttar Kashi, India. J Commun Dis 2004; 36(4): 233-239. 